\title{
Anthropometric indices predict physical function and mobility in older Australians: the Australian Longitudinal Study of Ageing
}

\author{
Elaine Bannerman ${ }^{1}$, Michelle D Miller ${ }^{2}$, Lynne A Daniels ${ }^{1}$, Lynne Cobiac ${ }^{3}$, Lynne C Giles ${ }^{4}$, \\ Craig Whitehead ${ }^{2}$, Gary R Andrews ${ }^{5}$ and Maria Crotty ${ }^{2, *}$ \\ 'Department of Public Health, Flinders University of South Australia: ${ }^{2}$ Rehabilitation \& Ageing Studies Unit, Flinders \\ University of South Australia, Adelaide, South Australia: ${ }^{3} \mathrm{CSIRO}$ Health Sciences and Nutrition Adelaide, South \\ Australia: ${ }^{4}$ Computing Services, Flinders University of South Australia: ${ }^{5}$ Centre for Ageing Studies, Flinders University \\ of South Australia
}

Submitted 8 October 2001: Accepted 1 February 2002

\begin{abstract}
Objective: To evaluate, in terms of function and mobility, the predictive value of commonly adopted anthropometric 'definitions' used in the nutritional assessment of older adults, in a cohort of older Australians.

Design: Prospective cohort study - Australian Longitudinal Study of Ageing (ALSA). Setting: Adelaide, South Australia (1992-1994).

Subjects: Data were analysed from 1272 non-institutionalised (685 males, 587 females) older adults $\geq 70$ years old in South Australia. Seven 'definitions' commonly used in the anthropometric assessment of both under- and overnutrition (including four using body mass index (BMI), waist-to-hip ratio, waist circumference and percentage weight change) were evaluated at baseline, for their ability to predict functional and mobility limitation assessed (by self-report questionnaire) at two years follow-up. All questionnaires were administered and anthropometry performed by trained investigators. The associations between the definitions and decline in mobility and physical function were evaluated over two years using multiple logistic regression. Results: $\mathrm{A}$ BMI $>85$ th percentile or $>30 \mathrm{~kg} \mathrm{~m}^{-2}$ or a waist circumference of $>102 \mathrm{~cm}$ in males and $>88 \mathrm{~cm}$ in females increased risk of functional and mobility limitations. Over two years, a loss of $10 \%$ body weight significantly increased the risk of functional and mobility limitations.

Conclusion: Maintaining weight within older adults, irrespective of initial body weight, may be important in preventing functional and mobility limitations. Excessive weight is associated with an increased risk of limitation in function and mobility, both key components of health-related quality of life.
\end{abstract}

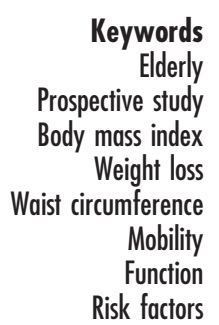

There is evidence to suggest that malnutrition (both underand overnutrition) is common in older adults ${ }^{1}$. The consequences of malnutrition have been described in different settings as adversely affecting health outcomes, including mobility ${ }^{2,3}$, health-related quality of life $^{4,5}$ and life expectancy ${ }^{6-10}$. It is imperative that clinically significant malnutrition can be reliably detected in order to cost-effectively target and evaluate nutritional interventions.

Anthropometric methods of nutritional assessment are probably the most widely used ${ }^{11}$ and are a simple, cheap and potentially reliable method for evaluating nutritional status in older adults in a range of settings. However, there are problems with these methods in old age, with little information existing to guide the interpretation of anthropometric data. Most notable are concerns over the appropriateness of existing reference data or lack thereof ${ }^{12-14}$ and debate as to whether statistically derived cut-off points for anthropometric variables are valid indicators of undernutrition ${ }^{12,15}$. Whilst there are some data for mortality as an outcome ${ }^{6-10}$, appropriate reference or cut-off values for anthropometric variables that predict the loss of physical function and mobility for older adults are limited.

Existing reference ranges to assess the nutritional status of older adults, for both over- and undernutrition, have been drawn from studies investigating younger adults ${ }^{16,17}$ or are based on statistically defined values ${ }^{18,19}$ rather than outcome data such as morbidity, mortality or quality of life from large longitudinal population studies of older adults. To date, there is a paucity of population- and age-specific reference data of anthropometric measures for older Australians and limited data to determine which values have significant clinical or biological meaning. 
The aim of this study was to use data from the Australian Longitudinal Study of Ageing (ALSA) to investigate the prognostic value of a number of commonly used anthropometric indices or definitions of poor nutritional status (both over- and undernutrition) in terms of physical function and mobility. These outcomes have the potential to lead to loss of independence in older adults.

\section{Subjects and methods}

\section{Description of the Australian Longitudinal Study of Ageing}

A longitudinal study aimed at identifying factors that contribute to and predict the health and social well-being of older Australians was commenced in 1992. The design of the study is described in detail elsewhere ${ }^{20}$. Baseline data collection (Wave 1) was conducted via personal interviews, observed home-based assessments of physiological functions, self-completed questionnaires and clinical assessment ${ }^{21}$ including anthropometric measurements. Two years after the baseline data collection, subjects were followed up with a second personal interview that included a repeat clinical assessment (Wave 3).

\section{Subjects}

The sample was randomly selected from the State Electoral Database, which includes all residents over 18 years old in the Adelaide, South Australia Statistical Division. The rate at which respondents were recruited varied by their sex, age and region of residence in an attempt to get a representative sample of the older adult population. Overall, there were 1799 community-dwelling older adults aged over 70 years who agreed to participate in the baseline collection of data, of which 1396 (78\%) also participated in a detailed clinical assessment. Only data from the 1272 participants who survived and agreed to take part in the second interview were included in the analyses presented in this paper.

\section{Antbropometric measures and predictor indices}

Baseline (Wave 1) anthropometric measurements were performed by trained observers in subjects' own homes using the methods described by the World Health Organization (WHO) ${ }^{22}$. Measurements of height (to the nearest $0.1 \mathrm{~cm}$ ) were made using a portable stadiometer and body weight (to the nearest $0.1 \mathrm{~kg}$ ) using portable scales. Subjects were measured in light clothing without shoes. Commonly used nutritional assessment indices were calculated using these anthropometric measures. Body mass index (BMI; weight $(\mathrm{kg}) /$ height $(\mathrm{m})^{2}$ ) is used as an indicator of both undernutrition and overnutrition. The 'definitions' for BMI evaluated in this paper include 'desirable' or $20-25 \mathrm{~kg} \mathrm{~m}^{-2}$ (Refs. 17, 23), 15-85th percentile (Ref. 3), 22-25 $\mathrm{kg} \mathrm{m}^{-2}$ (Ref. 24) and $\leq 30 \mathrm{~kg} \mathrm{~m}^{-2}$ (Ref. 25). Waist circumference (cm) and hip circumference $(\mathrm{cm})$ are often used to assess overnutrition, central obesity and cardiovascular risk $^{23}$. These were measured at the mid-point between the costal border and the iliac crest and at the level of the greatest protuberance of the buttocks respectively, and waist-to-hip ratio (WHR) calculated. The 'definitions' for waist circumference and WHR evaluated are those recommended by the WHO. Waist circumference measurements of $<94 \mathrm{~cm}$ for males and $<80 \mathrm{~cm}$ for females were classified as 'desirable'; 94$102 \mathrm{~cm}$ for males and $80-88 \mathrm{~cm}$ for females were classified as 'increased obesity-associated risk'; and $>102 \mathrm{~cm}$ for males and $>88 \mathrm{~cm}$ for females were classified as 'substantially increased obesity-associated risk'. WHR measurements of $<1.0$ for males and $<0.85$ for females were classified as 'desirable'; $\geq 1.0$ for males and $\geq 0.85$ for females were classified as 'leading to increased risk' ${ }^{23}$. Percentage weight change is more commonly associated with the assessment of undernutrition. Percentage weight change (weight $(\mathrm{kg})$ at two years post-baseline minus weight $(\mathrm{kg})$ at baseline/weight $(\mathrm{kg})$ at baseline $\times 100)$ was evaluated using the following categories: stable $( \pm 5 \%)$; gain of $>5 \%$; loss of $5-10 \%$; loss of $>10 \%$.

\section{Health outcomes}

Mobility and physical function were both assessed by means of self-report using items by Rosow and Breslau ${ }^{26}$ for mobility and $\mathrm{Nagi}^{27}$ for physical function, at baseline and again two years later. These questionnaires have been used in a number of similar studies and are reliable ${ }^{28}$. The mobility items included self-assessment of individual ability to walk up and down stairs to the second floor and walk half a mile without help. Subjects answered either 'yes' or 'no' to each of these questions. Mobility was dichotomised for subsequent analyses, with no limitation defined as subjects reporting 'being able to climb stairs and walk half a mile' and limitation defined as subjects reporting 'either or both of these activities could not be completed'. The assessment of physical function ${ }^{27}$ used a five-point Likert scale. This included questions about individual ability to pull or push large objects; stoop, crouch and kneel; lift weights over 10 pounds; extend arms above shoulder level and handle small objects. Subjects self-reported whether they had 'no difficulty at all', 'a little difficulty', 'some difficulty', 'a lot of difficulty' or 'just unable to do' five measures of upper- and lower-body function. Physical function was dichotomised for subsequent analyses. No limitation was defined as reporting 'no more than a little difficulty' for all five component questions. Limitation was defined as reporting 'some difficulty', 'a lot of difficulty' or 'unable to do it' for at least one of the five component questions ${ }^{29}$.

Ethical approval was obtained from Flinders Clinical Investigation (Ethics) Committee. Written informed consent was obtained from each subject. 


\section{Statistical metbods and analysis}

Mann-Whitney $U$-tests and chi-square tests of association were used to test for gender differences in the anthropometric measures. Separate logistic regressions were then fitted, taking mobility and physical function as the response variables and BMI, waist circumference, WHR and percentage weight change as potential predictor variables. Gender, age group (70-74, 75-79, 80-84 and $85+$ years), marital status, smoking status, self-rated health (poor-fair, good, very good, excellent), number of selfrated co-morbid conditions (range $0-10$ ), independence in basic activities of daily living (BADL; independent in $\mathrm{BADL}$, requires assistance with $>1 \mathrm{BADL})^{30}$, depressive symptomatology $^{31}$ (range 0-48) and cognition ${ }^{32}$ (no impairment $\geq 17$, impaired $<17$ ) were identified as potential confounders, and included in the logistic regression analyses. Baseline BMI, baseline mobility (limitation, no limitation) and baseline physical function (limitation, no limitation) were each entered as potential confounders in the corresponding regression analyses where weight change, mobility and physical function at two years follow-up were the response variables. A regression model incorporating all of the potential confounding variables was fitted to the data. All potential confounding variables were treated as categorical with the exception of co-morbidity (range 0-10) and depressive symptomatology (range 0-48), which were treated as continuous.

All analyses were conducted using the SPSS statistical package version 9.0 (SPSS, Inc., 1998). All results are presented with 95\% confidence intervals (CIs) and statistical significance was set at $P<0.05$ throughout.

\section{Results}

\section{Sample characteristics at baseline}

Two years after the initial interview, 91\% $(n=1272)$ of the original sample were alive and all participated in the follow-up. The mean (standard deviation (SD)) age at baseline was $77.5(5.5)$ years; $54 \%(n=685)$ were male. The majority of the participants were born in Australia (69.2\%) with the second largest country of origin being the United Kingdom (20.7\%). Table 1 shows the sample characteristics by gender.

At baseline, compared with males, females were younger $(P=0.01)$ and a greater number were widowed $(P<0.001)$ and non-smokers $(P<0.001)$. Cognitive impairment $(P<0.01)$, depressive symptomatology $(P<$ $0.05)$, disability in physical function $(P<0.001)$ and mobility $(P<0.001)$ were more common for females than males. In addition, females were more likely to suffer from arthritis $(P=0.005)$ and hypertension $(P<0.001)$, whilst more males than females suffered from heart attack $(P=$ $0.001)$, ulcers $(P<0.05)$ and diabetes $(P<0.05)$ (Table 1$)$.

\section{Descriptive baseline data for antbropometric measures and predictor indices}

Table 2 details descriptive baseline data for the performed anthropometric measurements and calculated indices. Males were taller $(P<0.001)$ and heavier $(P<0.001)$ than females; however, there was no significant difference in mean BMI $(P>0.05)$. Waist circumference $(P<0.001)$ and WHR $(P<0.001)$ were significantly greater for males as compared with females.

\section{Predictor indices and association with bealth outcomes}

\section{Body mass index}

Individuals with a baseline BMI suggestive of being underweight $\left(<20 \mathrm{~kg} \mathrm{~m}^{-2}, \quad<15\right.$ th percentile or $<22 \mathrm{~kg} \mathrm{~m}^{-2}$ ) had a reduced risk of limited physical function at two years follow-up compared with individuals with a baseline BMI in the desirable range (odds ratio (OR) $0.31, \quad 95 \% \quad \mathrm{CI}=0.15-0.67 ; \quad \mathrm{OR}=0.56, \quad 95 \% \quad \mathrm{CI}=$ $0.36-0.85$; and $\mathrm{OR}=0.63,95 \% \mathrm{CI}=0.40-0.99$, respectively). Conversely, those individuals with a baseline BMI suggestive of overweight $\left(>25 \mathrm{~kg} \mathrm{~m}^{-2},>85\right.$ th percentile, $>26 \mathrm{~kg} \mathrm{~m}^{-2}$ or $>30 \mathrm{~kg} \mathrm{~m}^{-2}$ ) had an increased risk of limitation in physical function at two years follow-up compared with their contemporaries with a BMI within the desirable range $(\mathrm{OR}=1.37,95 \% \mathrm{CI}=1.00-1.86 ; \mathrm{OR}=$ $1.69, \quad 95 \% \quad \mathrm{CI}=1.06-2.69 ; \quad \mathrm{OR}=1.44, \quad 95 \% \quad \mathrm{CI}=$ $1.05-1.99$; and $\mathrm{OR}=1.90,95 \% \mathrm{CI}=1.19-3.05$, respectively) (Table 3).

Those individuals with a baseline BMI suggestive of overweight ( $>85$ th percentile, $>30 \mathrm{~kg} \mathrm{~m}^{-2}$ ) also showed an increased risk of limited mobility at two years follow-up compared with those with a BMI in the 'desirable' range $(\mathrm{OR}=2.08,95 \% \mathrm{CI}=1.34-3.23$ and $\mathrm{OR}=2.14,95 \%$ $\mathrm{CI}=1.38-3.32$, respectively). A baseline BMI suggestive of underweight did not predict any significant change in mobility status at two years follow-up, as compared with a BMI within the desirable range (Table 4).

\section{Weight change}

Individuals with a weight loss of $>10 \%$ over two years had an increased risk of limitation in physical function (OR $=$ 2.96, 95\% CI $=1.41-6.20)$ and mobility $(\mathrm{OR}=2.22,95 \%$ $\mathrm{CI}=1.16-4.26$ ) (Tables 3 and 4 ) as compared with those whose weight remained stable ( $\pm 5 \%$ weight change). Individuals who lost between 5 and 10\% body weight over the two years' follow-up were more likely to have limited mobility $(\mathrm{OR}=1.73,95 \% \mathrm{CI}=1.10-2.71)$ than those whose weight remained stable ( $\pm 5 \%$ weight change) (Table 4).

Waist circumference and WHR

Individuals with a high waist circumference at baseline $(>102 \mathrm{~cm}$ males, $>88 \mathrm{~cm}$ females) had an increased risk of limitation in physical function at two years follow-up 
Table 1 Baseline characteristics by gender of non-institutionalised Australians $\geq 70$ years old $(n=1272)$

\begin{tabular}{|c|c|c|}
\hline Characteristic & $\begin{array}{c}\text { Males } \\
(n=685)\end{array}$ & $\begin{array}{l}\text { Females } \\
(n=587)\end{array}$ \\
\hline \multicolumn{3}{|l|}{ Age (years)* } \\
\hline Mean (SD) & $77.9(5.6)$ & $77.1(5.5)$ \\
\hline Range & $70-93$ & $70-103$ \\
\hline \multicolumn{3}{|l|}{ Marital status (\%)† } \\
\hline Married/de facto & 74 & 63 \\
\hline Widowed & 19 & 32 \\
\hline Divorced/never married & 7 & 5 \\
\hline \multicolumn{3}{|l|}{ Smoking status $(\%) \dagger$} \\
\hline Never smoked & 29 & 71 \\
\hline Ex-smoker & 63 & 23 \\
\hline Current smoker & 8 & 6 \\
\hline \multicolumn{3}{|l|}{ Morbid conditions } \\
\hline Median number (range) & $1(0-7)$ & $1(0-8)$ \\
\hline Arthritis (\%)‡ & 48 & 56 \\
\hline Hypertension (\%)† & 21 & 31 \\
\hline Any cancer (\%) & 20 & 19 \\
\hline Heart condition (\%) & 13 & 16 \\
\hline Hernia (\%) & 14 & 15 \\
\hline Respiratory disease (\%) & 11 & 10 \\
\hline Diabetes (\%)‡ & 7 & 4 \\
\hline Ulcers (\%)‡ & 7 & 4 \\
\hline Heart attack (\%)‡ & 6 & 2 \\
\hline Stroke (\%) & 3 & 3 \\
\hline \multicolumn{3}{|l|}{ Self-rated health (\%) } \\
\hline Very good-excellent & 42 & 40 \\
\hline Good & 30 & 32 \\
\hline Fair-poor & 28 & 28 \\
\hline \multicolumn{3}{|l|}{ Cognition (\%)‡ } \\
\hline Impaired: score $<17$ & 16 & 22 \\
\hline \multicolumn{3}{|l|}{ Depressive symptomatology ${ }^{*}$} \\
\hline Median (range) & $6.0(0-43)$ & $6.0(0-48)$ \\
\hline \multicolumn{3}{|l|}{ Basic activities of daily living (BADL) status (\%) } \\
\hline Independent in all BADLs & 90 & 86 \\
\hline Requiring assistance with at least 1 BADL & 10 & 14 \\
\hline \multicolumn{3}{|l|}{ Physical function $(\%) \dagger$} \\
\hline Physical function limitation & 47 & 65 \\
\hline \multicolumn{3}{|l|}{ Mobility (\%)‡ } \\
\hline Mobility limitation & 19 & 31 \\
\hline
\end{tabular}

* Significant gender difference, $P<0.05$, (Mann-Whitney $U$-test).

† Significant gender difference, $P<0.001$ (Pearson chi-square test of association).

$\ddagger$ Significant gender difference, $P<0.05$ (Pearson chi-square test of association).

$(\mathrm{OR}=1.86,95 \% \mathrm{CI}=1.30-2.65)$. There was no predictive relationship identified between waist circumference or WHR and limitation in mobility at two years.

\section{Discussion}

Traditionally, clinicians make an assessment of nutritional status based on a combination of variables that often include clinical assessment, biochemical measures, anthropometric indicators of fat-free and fat mass, changes in body weight and an assessment of dietary intake. However, frequently anthropometric measures and indices are used independently, and yet there is a dearth of information about whether the methods of interpretation or commonly used 'definitions' have any validity in predicting health outcomes in older adults. The current

Table 2 Baseline anthropometric parameters by gender for non-institutionalised Australians $\geq 70$ years old $(n=1272)$

\begin{tabular}{|c|c|c|c|c|}
\hline \multirow[b]{2}{*}{ Anthropometric parameter } & \multicolumn{2}{|r|}{ Males } & \multicolumn{2}{|r|}{ Females } \\
\hline & $n$ & Mean \pm SD (range) & $n$ & Mean \pm SD (range) \\
\hline Weight $(\mathrm{kg})^{*}$ & 680 & $74.8 \pm 11.6(38.0-117.0)$ & 580 & $63.6 \pm 11.3(29.0-109.0)$ \\
\hline Height $(m)^{*}$ & 679 & $1.70 \pm 0.07(1.49-1.90)$ & 577 & $1.56 \pm 0.06(1.38-1.74)$ \\
\hline Body mass index $\left(\mathrm{kg} \mathrm{m}^{-2}\right)$ & 679 & $25.98 \pm 3.50(14.0-41.0)$ & 577 & $26.14 \pm 4.45(15.0-48.0)$ \\
\hline Waist-to-hip ratio* & 662 & $0.95 \pm 0.06(0.76-1.13)$ & 560 & $0.84 \pm 0.07(0.67-1.29)$ \\
\hline Waist girth $(\mathrm{cm})^{*}$ & 664 & $97.2 \pm 9.72(64.0-129.5)$ & 564 & $86.5 \pm 11.2(56.0-135.0)$ \\
\hline$\%$ Weight change (two years) & 556 & $-1.3 \pm 5.9(-32.9$ to +28.6$)$ & 481 & $-0.8 \pm 6.6(-29.6$ to +48.1$)$ \\
\hline
\end{tabular}

* Significant gender difference, $P<0.001$ (independent samples $t$-test). 
Table 3 Odds ratios of limitation in physical function ${ }^{*}$ at two years follow-up, adjusted for potential confounding variables $†$ in noninstitutionalised Australians $\geq 70$ years old

\begin{tabular}{|c|c|c|c|c|}
\hline Anthropometric index & $n$ & OR & $95 \% \mathrm{Cl}$ & $P$-value \\
\hline \multicolumn{5}{|l|}{ Body mass index } \\
\hline $20-25 \mathrm{~kg} \mathrm{~m}^{-2}$ & 428 & 1.00 & & \\
\hline$<20 \mathrm{~kg} \mathrm{~m}^{-2}$ & 47 & 0.31 & $0.15-0.67$ & $0.002 \ddagger$ \\
\hline$>25 \mathrm{~kg} \mathrm{~m}^{-2}$ & 631 & 1.37 & $1.00-1.86$ & $0.048 \ddagger$ \\
\hline 15-85th percentile§ & 793 & 1.00 & & \\
\hline$<15$ th percentile & 167 & 0.56 & $0.36-0.85$ & $0.007 \ddagger$ \\
\hline$>$ 85th percentile & 160 & 1.69 & $1.06-2.69$ & $0.028 \ddagger$ \\
\hline $22-26 \mathrm{~kg} \mathrm{~m}^{-2}$ & 423 & 1.00 & & \\
\hline$<22 \mathrm{~kg} \mathrm{~m}^{-2}$ & 166 & 0.63 & $0.40-0.99$ & $0.048 \ddagger$ \\
\hline$>26 \mathrm{~kg} \mathrm{~m}^{-2}$ & 532 & 1.44 & $1.05-1.99$ & $0.025 \ddagger$ \\
\hline$\leq 30 \mathrm{~kg} \mathrm{~m}^{-2}$ & 970 & 1.00 & & \\
\hline$>30 \mathrm{~kg} \mathrm{~m}^{-2}$ & 151 & 1.90 & $1.19-3.05$ & $0.007 \ddagger$ \\
\hline \multicolumn{5}{|l|}{$\%$ Weight change (two years) } \\
\hline Stable $( \pm 5 \%)$ & 654 & 1.00 & & \\
\hline Gained $>5 \%$ & 122 & 1.02 & $0.62-1.67$ & 0.945 \\
\hline Lost $5-10 \%$ & 156 & 1.57 & $0.99-2.48$ & 0.055 \\
\hline Lost $>10 \%$ & 58 & 2.96 & $1.41-6.20$ & $0.004 \ddagger$ \\
\hline \multicolumn{5}{|l|}{ Waist circumference } \\
\hline Desirableq & 369 & 1.00 & & \\
\hline Increased risk & 336 & 1.06 & $0.74-1.52$ & 0.759 \\
\hline Substantially increased risk* & 431 & 1.86 & $1.30-2.65$ & $0.001 \ddagger$ \\
\hline \multicolumn{5}{|l|}{ Waist-to-hip ratio } \\
\hline Desirable†† & 794 & 1.00 & & \\
\hline 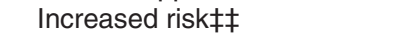 & 213 & 1.47 & $0.93-2.34$ & 0.099 \\
\hline
\end{tabular}

${ }^{*}$ Physical function measured upper- and lower-body function. No limitation in physical function defined as reporting no more than a little difficulty for all five measures, limitation defined as reporting some difficulty, a lot of difficulty or unable to do task for a least one of the five measures.

†Adjusted for baseline age, gender, marital status, smoking, self-rated health, sum of morbid conditions, physical function, basic activities of daily living, cognition and depressive symptomatology.

$\ddagger$ Significant difference compared with desirable reference range.

$\S$ Body mass index: 15 th percentile $=22 \mathrm{~kg} \mathrm{~m}^{-2}$ and 85 th percentile $=29.9$

$\mathrm{kg} \mathrm{m}^{-2}$.

I Waist circumference of $<94 \mathrm{~cm}$ (males) and $<80 \mathrm{~cm}$ (females).

\|W Waist circumference of $94-102 \mathrm{~cm}$ (males) and $80-88 \mathrm{~cm}$ (females).

${ }^{\star *}$ Waist circumference of $>102 \mathrm{~cm}$ (males) and $>88 \mathrm{~cm}$ (females).

†† Waist-to-hip ratio of $\leq 1.0$ (males) and $\leq 0.85$ (females).

抽Waist-to-hip ratio of $>1.0$ (males) and $>0.85$ (females).

study has evaluated, in terms of physical function and mobility, the predictive value of a number of these commonly used definitions of nutritional status for the first time in a non-institutionalised cohort of older Australians aged at least 70 years.

Our findings suggest that anthropometric indices that represent overweight or obesity (BMI $\geq 30 \mathrm{~kg} \mathrm{~m}^{-2}$, BMI > 85th percentile, waist circumference of $>102 \mathrm{~cm}$ for males or $>88 \mathrm{~cm}$ for females $)^{23,25}$ predicted a $69-90 \%$ increased risk of limitation in both physical function and mobility at two years follow-up. However, a high WHR was not shown to predict functional or mobility limitation. It is well established that waist circumference predicts an increased risk of coronary heart disease (CHD), diabetes and stroke in middle-aged adults ${ }^{23,33,34}$, but, to our knowledge, there have been no studies that have evaluated this nutritional index or WHR in terms of predicting function or mobility status. As is now apparent in the assessment of risk for CHD, the addition of the measurement of hip circumference does little to enhance the prognostic value of the
Table 4 Odds ratios of mobility limitation* at two years follow-up, adjusted for potential confounding variablest in non-institutionalised Australians $\geq 70$ years old

\begin{tabular}{|c|c|c|c|c|}
\hline Anthropometric index & $n$ & OR & $95 \% \mathrm{Cl}$ & $P$-value \\
\hline \multicolumn{5}{|l|}{ Body mass index } \\
\hline $20-25 \mathrm{~kg} \mathrm{~m}^{-2}$ & 425 & 1.00 & & \\
\hline$<20 \mathrm{~kg} \mathrm{~m}^{-2}$ & 47 & 0.87 & $0.39-1.93$ & 0.723 \\
\hline$>25 \mathrm{~kg} \mathrm{~m}^{-2}$ & 632 & 1.31 & $0.95-1.82$ & 0.104 \\
\hline 15-85th percentile§ & 791 & 1.00 & & \\
\hline$<15$ th percentile & 167 & 0.72 & $0.46-1.14$ & 0.164 \\
\hline$>85$ th percentile & 160 & 2.08 & $1.34-3.23$ & $0.001 \ddagger$ \\
\hline $22-26 \mathrm{~kg} \mathrm{~m}^{-2}$ & 419 & 1.00 & & \\
\hline$<22 \mathrm{~kg} \mathrm{~m}^{-2}$ & 166 & 0.74 & $0.45-1.21$ & 0.229 \\
\hline$>26 \mathrm{~kg} \mathrm{~m}^{-2}$ & 534 & 1.29 & $0.92-1.81$ & 0.142 \\
\hline$\leq 30 \mathrm{~kg} \mathrm{~m}^{-2}$ & 968 & 1.00 & & \\
\hline$>30 \mathrm{~kg} \mathrm{~m}^{-2}$ & 151 & 2.14 & $1.38-3.32$ & $0.001 \ddagger$ \\
\hline \multicolumn{5}{|l|}{$\%$ Weight change (two years) } \\
\hline Stable $( \pm 5 \%)$ & 654 & 1.00 & & \\
\hline Gained $>5 \%$ & 121 & 0.74 & $0.42-1.30$ & 0.298 \\
\hline Lost $5-10 \%$ & 155 & 1.73 & $1.10-2.71$ & $0.017 \ddagger$ \\
\hline Lost $>10 \%$ & 59 & 2.22 & $1.16-4.26$ & $0.016 \ddagger$ \\
\hline \multicolumn{5}{|l|}{ Waist circumference } \\
\hline Desirableף & 377 & 1.00 & & \\
\hline Increased risk\| & 348 & 1.07 & $0.72-1.59$ & 0.731 \\
\hline Substantially increased risk ${ }^{* *}$ & 455 & 1.43 & $0.99-2.08$ & 0.058 \\
\hline \multicolumn{5}{|c|}{ Waist-to-hip ratio } \\
\hline Desirablet† & 794 & 1.00 & & \\
\hline 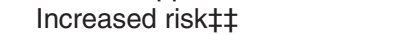 & 211 & 0.77 & $0.49-1.21$ & 0.260 \\
\hline
\end{tabular}

* Mobility limitation measured ability to walk up stairs and over distance. No limitation defined as being able to climb stairs and walk half a mile, limitation defined as subjects reporting that either or both of these activities could not be completed.

†Adjusted for baseline age, gender, marital status, smoking, self-rated health, sum of morbid conditions, mobility, basic activities of daily living, cognition and depressive symptomatology.

‡ Significant difference compared with desirable reference range.

§Body mass index: 15 th percentile $=22 \mathrm{~kg} \mathrm{~m}^{-2}$ and 85th percentile $=29.9$ $\mathrm{kg} \mathrm{m}^{-2}$.

In Waist circumference of $<94 \mathrm{~cm}$ (males) and $<80 \mathrm{~cm}$ (females).

\|Waist circumference of $94-102 \mathrm{~cm}$ (males) and $80-88 \mathrm{~cm}$ (females).

${ }^{* *}$ Waist circumference of $>102 \mathrm{~cm}$ (males) and $>88 \mathrm{~cm}$ (females).

†† Waist-to-hip ratio of $\leq 1.0$ (males) and $\leq 0.85$ (females).

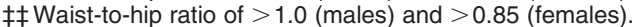

index ${ }^{23,35}$. Similar findings regarding the relationship seen between obesity (as determined using BMI) and mobility in older adults have been reported in two large prospective US epidemiological studies ${ }^{2,3}$. These studies have suggested that those individuals in the upper quintile for BMI (corresponding to BMI $\left.>28.1 \mathrm{~kg} \mathrm{~m}^{-2}\right)^{3}$ or with $\quad$ BMI $>80$ th percentile (corresponding to BMI $\left.>27 \mathrm{~kg} \mathrm{~m}^{-2}\right)^{2}$ have a two-fold or $20 \%$ increased risk of mobility-disability at four years of follow-up, respectively. A high BMI may be a proxy index for inactivity; however, this was controlled for in the study by LaCroix and colleagues ${ }^{2}$. Excess body mass may increase wear and tear on joints, putting the individual at increased risk of osteoarthritis and thus reducing physical activity levels that in turn may lead to further weight gain. However, it should be noted that in the study by LaCroix et al. $^{2}$ all heights and weights were self-reported as opposed to being measured. Limitations in the use of selfreported height and weight have been shown to increase in adults $>60$ years old with subsequent misclassification 
of overweight status ${ }^{36}$. The BMI cut-off point at which an increased risk in mobility is seen is likely to vary from population to population due to geographical or ethnic differences in body composition ${ }^{12,13}$.

A BMI suggestive of underweight $\left(<22 \mathrm{~kg} \mathrm{~m}^{-2}\right.$ (Ref. 23) or $<15$ th percentile) showed a reduced risk of developing a limitation in physical function by $37 \%$ or $44 \%$, respectively, but not mobility. The relationship between nutritional status and the development of functional impairment in older adults has been investigated with conflicting results ${ }^{37-39}$. Increased dependency has been observed solely in those individuals considered to be underweight $\quad\left(\mathrm{BMI}<22 \mathrm{~kg} \mathrm{~m}^{-2} \quad\right.$ (Ref. 40), $\quad$ BMI $<$ $16 \mathrm{~kg} \mathrm{~m}^{-2}$ (Ref. 41)) or only in those individuals considered to be obese $\mathrm{e}^{38,42}$, whilst in other studies an increased risk of physical functional impairment was seen at both extremes of BMI $\left(<21 \mathrm{~kg} \mathrm{~m}^{-2} \text { and }>30 \mathrm{~kg} \mathrm{~m}^{-2}\right)^{39}$. It is worthy of note that a number of these studies have been cross-sectional in nature ${ }^{38,39,43}$. Discrepancies between the findings of these studies may be explained by the fact that different assessment techniques and definitions of functional limitation have been used, or they may reflect differences in the health status of the subjects or populations studied.

Weight loss over time could suggest frailty and an increased susceptibility to disability resulting from diminished muscle mass. However, how large a weight loss is significant? Some authors report increased risk associated with the loss of an absolute amount of weight ${ }^{43}$, whilst others refer to a significant percentage weight loss ${ }^{3}$. A weight loss of less than $5 \%$ is likely to be associated with the natural loss of body weight with advancing age ${ }^{44}$. The findings from the current study suggest that between 5 and $10 \%$ weight loss over two years is associated with a $57 \%$ and $73 \%$ increased risk of limitation in physical function and mobility, respectively. Greater than 10\% weight loss over two years is associated with a two-to-three times increased risk of limitation in physical function and mobility, even after controlling for smoking, disease status and BMI at baseline. These findings are similar to those reported from the National Health and Nutrition Examination Survey (NHANES) ${ }^{3}$, where community-dwelling older adults with a greater than 5\% weight loss had a two-fold increase in risk of disability compared with those whose weight was stable. In both studies, a weight loss of $>5 \%$ significantly increased the risk of functional and mobility limitation, irrespective of initial BMI. It is postulated that the weight loss seen in these studies is more likely to be involuntary than voluntary weight loss (the former generally not recovered). However, whether weight loss was volitional or otherwise has not been recorded. Also unknown is whether this weight loss was predominately fat mass or lean body mass. Analyses of the Framingham Heart Study and Tecumseh Community Health studies showed general weight loss to be associated with increased mortality whilst loss of fat mass, as indicated using skinfold measurements, was associated with decreased mortality ${ }^{45}$. It may be suggested that older adults who remain overweight in their later years may be best advised to maintain their weight rather than be counselled on weight loss strategies, or intervention strategies for weight loss be coupled with exercise or activity programmes so as to help preserve lean body mass. However, intervention strategies that focus on ensuring adults enter old age at a healthy BMI may not only reduce the risk of impaired function and mobility in later life, but would also help address the ill health and premature mortality associated with obesity and cardiovascular diseases.

Generally, greater emphasis is given to underweight compared with overweight as the major nutritional problem in old age ${ }^{46,47}$. Our data suggest that to optimise independence and mobility, older persons should avoid entering old age 'obese' and that the maintenance of a steady weight may be critical for the maintenance of normal physical function. We would argue that greater attention should be given to overweight or obesity as a problem in old age, as it is an important predictor for the loss of good physical function. However, the reduction of BMI in those older adults classified as overweight may not be an effective strategy for avoiding functional or mobility impairment, although the nature of the weight loss needs further investigation.

The current study has a number of strengths. The prospective nature of the study has allowed predictive analyses for a number of anthropometric variables. Recruitment of the sample was stratified by age, gender and residence location to provide a representative cohort of older adults in South Australia, with a high (91\%) follow-up of individuals at two years. In addition, body weight, height, waist and hip circumference were all measured by trained clinical observers rather than being self-reported, as is common in large cohort studies of this nature ${ }^{2,37}$. It is known that self-reported anthropometric variables are potentially subject to significant error, especially in older individuals, and thus subsequent misclassification of body weight status may occur ${ }^{36}$. Further, a range of potential confounders was controlled for in the regression models, including baseline BMI and disease status, which enabled independent evaluation of the effects of predictor variables. However, limitations of this study include the possible self-misclassification of health status and the self-reported measures of physical function and mobility. Nevertheless this is the approach that has been adopted in the majority of previously reported studies ${ }^{28,29}$, although a more objective measure of disability may result in different conclusions.

It would appear that the 'desirable' range for BMI based on health outcomes is different and likely to be higher in older adults compared with younger adults. This is likely in part to be the result of changes that occur in body composition with advancing age ${ }^{48}$. Issues associated with 
obtaining an accurate and reliable height measurement in older adults cannot be overlooked. To overcome these problems, alternatives such as knee-height and indices such as the mindex and demiquet ${ }^{49}$ or weight $/$ knee height $^{50}$ may be more appropriate. The prognostic value of such indices needs to be evaluated to determine appropriate methods of interpretation.

In conclusion, these results suggest that maintaining a stable weight in older Australian adults could be important in preventing functional and mobility limitations. Weight loss of $>10 \%$ body weight, over two years, independent of baseline BMI and a range of other potential confounders including health status, is significant in terms of poor functional outcomes. It is suggested that intervention strategies to lose weight (specifically body fat) also need to address activity or exercise strategies that can help to maintain or improve lean body mass, strength, mobility and function. Overweight classified by a BMI of more than $30 \mathrm{~kg} \mathrm{~m}^{-2}$ or a waist circumference of more than $102 \mathrm{~cm}$ for males and more than $88 \mathrm{~cm}$ for females may be useful and practical tools to identify older Australian adults who have an increased risk of impaired physical function and mobility. The use of waist circumference may be particularly useful in those individuals where a measure of weight cannot be obtained. Hence, assessment of BMI, weight change and waist circumference should be included as standard in community geriatric assessments. Further research is required to investigate the predictive value of the aforementioned cut-off points in institutionalised older adults.

\section{Acknowledgements}

The authors gratefully acknowledge the work of Professor Mary Luscsz and the project team at the Centre for Ageing Studies, Flinders University of South Australia, who carried out the Australian Longitudinal Study of Ageing and provided data for this paper.

This study was supported in part by the South Australian Health Commission, the Australian Rotary Health Research Fund and by a grant from the US National Institutes of Health (grant no. AG 08523-02).

Authors' contributions: GRA designed the study and critically revised the paper; EB, MDM, LAD, LC, LCG, CW and MC analysed and interpreted the data and critically revised the paper.

No disclaimers apply.

\section{References}

1 Morgan DB, Newton HM, Schorah CJ, Jewitt MA, Hancock MR, Hullin RP. Abnormal indices of nutrition in the elderly: a study of different clinical groups. Age \& Ageing 1986; 15(2): $65-76$.

2 LaCroix A, Guralnik J, Berkman L, Wallace R, Satterfield S. Maintaining mobility in late life. Am. J. Epidemiol. 1993; 137(8): 858-69.
3 Launer L, Harris T, Rumpel C, Madans J. Body mass index, weight change, and risk of mobility disability in middle-aged and older women: the epidemiologic follow-up study of NHANES I. J. Am. Med. Assoc. 1994; 271(14): 1093-8.

4 Ponzer S, Tidermark J, Brismar K, Soderqvist A, Cederholm T. Nutritional status, insulin-like growth factor-1 and quality of life in elderly women with hip fractures. Clin. Nutr. 1999; 18(4): 241-6.

5 Larsson J, Akerlind I, Permerth J, Hornqvist J. The relation between nutritional state and quality of life in surgical patients. Eur. J. Surg. 1994; 160(6-7): 329-34.

6 Campbell A, Spears G, Brown J, Busby W, Borrie M. Anthropometric measurements as predictors of mortality in a community population aged 70 years and over. Age E Ageing 1990; 19: 131-5.

7 Matilla K, Haavisto M, Rajala S. Body mass index and mortality in the elderly. Br. Med. J. 1986; 292: 867-8.

8 Harris T, Cook E, Garrison R, Higgins M, Kannel W, Goldman L. Body mass index and mortality among nonsmoking older persons. J. Am. Med. Assoc. 1988; 259(10): 1520-4.

9 Calle E, Thun M, Petrelli J, Rodriguez C, Health C. Body-mass index and mortality in a prospective cohort of US adults. N. Engl. J. Med. 1999; 341(15): 1097-105.

10 Sullivan DH, Walls RC, Lipschitz DA. Protein-energy undernutrition and the risk of mortality within $1 \mathrm{y}$ of hospital discharge in a select population of geriatric rehabilitation patients. Am. J. Clin. Nutr. 1991; 53(3): 599-605.

11 Gibson R. Principles of Nutritional Assessment. Oxford: Oxford University Press, 1990.

12 Bannerman E, Reilly JJ, MacLennan WJ, Kirk T, Pender F. Evaluation of validity of British anthropometric reference data for assessing nutritional state of elderly people in Edinburgh: cross sectional study. Br. Med. J. 1997; 315(7104): 338-41.

13 Launer LJ, Harris T. Weight, height and body mass index distributions in geographically and ethnically diverse samples of older persons. Ad Hoc Committee on the Statistics of Anthropometry and Aging. Age \& Ageing 1996; 25(4): 300-6.

14 Delarue J, Constans T, Malvy D, Pradignac A, Couet C, Lamisse F. Anthropometric values in an elderly French population. Br. J. Nutr. 1994; 71(2): 295-302.

15 Friedman P. A prospective comparison of methods to identify lethal wasting malnutrition. Nutr. Res. 1986; 6: $139-46$

16 James W, Ferro-Luzzi A, Waterlow J. Definition of chronic energy deficiency in adults. Eur. J. Clin. Nutr. 1988; 42 : 969-81.

17 Garrow J, Webster J. Quetelet's index $\left(W / H^{2}\right)$ as a measure of fatness. Int. J. Obes. 1985; 9: 147-53.

18 McWhirter J, Pennington C. Incidence and recognition of malnutrition in hospital. Br. Med. J. 1994; 308: 5-8.

19 World Health Organization (WHO). Use and Interpretation of Anthropometric Indicators of Nutritional Status. Report of a WHO Working Group, No. 64(b). Geneva: WHO, 1986.

20 Andrews G, Cheok F, Carr S. The Australian Longitudinal Study of Ageing. Aust. J. Ageing 1989; 8: 31-5.

21 Andrews G. The Australian Longitudinal Study of Ageing and a Collaborative Study of Aging in the US and Australia. Adelaide: Flinders University of South Australia, 1992.

22 World Health Organization (WHO). Physical Status: The Use and Interpretation of Anthropometry. Report of a WHO Expert Committee, No. 854. Geneva: WHO, 1995.

23 World Health Organization (WHO), Obesity: Preventing and Managing the Global Epidemic. Geneva: WHO, 3-5 June 1997.

24 Wahlqvist M. Food and Nutrition: Australasia, Asia and the Pacific. Sydney: Allen \& Unwin, 1997.

25 National Health and Medical Research Council. Dietary 
Guidelines for Older Australians. Canberra: National Health and Medical Research Council, 1999.

26 Rosow I, Breslau N. A Guttman health scale for the aged. J. Gerontol. 1966; 21(4): 556-9.

27 Nagi S. An epidemiology of disability among adults in the United States. Milbank Mem. Fund Quart. - Health \& Society 1976; 54(4): 439-67.

28 Smith LA, Branch LG, Scherr PA, Wetle TA, Evans DA, Herbert L, Taylor JO. Short-term variability of measures of physical function in older people. J. Am. Geriatr. Soc. 1990; 38: $993-8$.

29 Beckett LA, Brock DB, Lemke JH, Mendes de Leon CF, Guralnik JM, Fillenbaum GG, Branch LG, Wettle TT, Evans DA. Analysis of change in self-reported physical function among older persons in four population studies. Am. J. Epidemiol. 1996; 143: 766-78.

30 Katz S, Akpom C. A measure of sociobiological functions. Int. J. Health Serv. 1976; 6: 493-507.

31 Radloff L. The CES-D scale: a self-report depression scale for research in the general population. Appl. Psychol. Meas. 1977; 1: 385-401.

32 Folstein M, Folstein S, McHugh P. 'Mini-mental state'. A practical method for grading the cognitive state of patients for the clinician. J. Psychiat. Res. 1975; 12(3): 189-98.

33 Bjorntorp P. Classification of obese patients and complications related to the distribution of surplus fat. Am. J. Clin. Nutr. 1987; 45(5): 1120-5

34 Han T, van Leer E, Seidell J, Lean M. Waist circumference action levels in the identification of cardiovascular risk factors: prevalence study in a random sample. $\mathrm{Br}$. Med. J. 1995; 311(7017): 1401-5.

35 Lean $\mathrm{M}$, Han $\mathrm{T}$, Morrison C. Waist circumference as a measure for indicating need for weight management. $B r$. Med. J. 1995; 311: 158-61.

36 Kuczmarski M, Kuczmarski R, Najjar M. Effects of age on validity on self-reported height, weight and BMI: findings from the third National Health and Nutrition Examination Survey, 1988-1994. J. Am. Diet. Assoc. 2001; 101(1): 28-34.

37 Brill P, Giles W, Keenan N. Effect of body mass index on activity limitation and mortality among older women: the national health interview survey, 1986-1990. J. Women's Health 1997; 6(4): 435-40.
38 Ensrud K, Nevitt M, Yunis C. Correlates of impaired function in older women. J. Am. Geriatr. Soc. 1994; 42: 481-9.

39 Galanos A, Pieper C, Cornoni-Huntley J, Bales C, Fillenbaum G. Nutrition and function: is there a relationship between body mass index and the functional capabilities of community-dwelling elderly? J. Am. Geriatr. Soc. 1994; 42: $368-73$.

40 Landi F, Zuccala G, Gambassi G. Body mass index and mortality among older people living in the community. J. Am. Geriatr. Soc. 1999; 47: 1072-6.

41 Manandhar M, Anklesaria P, Myatt M, Ismail S. Undernutrition and functional ability amongst poor elderly people in urban India. Paper presented at Second European Congress on Nutrition and Health in the Elderly, Elsinore, Denmark, 1996.

42 Harris T, Kovar M, Suzman R. Longitudinal study of physical ability in the oldest-old. Am. J. Public Health 1989; 79: 698-702.

43 Jensen G, Kita K, Fish J, Heydt D, Frey C. Nutrition risk screening characteristics of rural older persons: relation to functional limitations and health care charges. Am. J. Clin. Nutr. 1997; 66(4): 819-28.

44 Baumgartner R. Body composition in elderly persons: a critical review of needs and methods. Prog. Food Nutr. Sci. 1993; 17(3): 223-60.

45 Allison DB, Zannolli R, Faith MS, Heo M, Pietrobelli A, VanItallie TB, Pi-Sunyer FX, Heymsfield SB. Weight loss increases and fat loss decreases all-cause mortality rate: results from two independent cohort studies. Int. J. Obes. 1999; 23: 603-11.

46 Lehmann A. Review: undernutrition in elderly people. Age $\&$ Ageing 1989; 18: 339-53.

47 Whitehead C, Giles L, Andrews G, Finucane P. Anthropometric and laboratory markers of nutritional status in a large sample of elderly Australians: the ALSA study. Aust.J. Ageing 2000; 19(2): 85-90.

48 Steen B. Body composition and ageing [review]. Nutr. Rev. 1988; 46(2): 45-51.

49 Lehmann A, Bassey E, Morgan K, Dallosso H. Normal values for weight, skeletal size and body mass indices in 890 men and women aged over 65 years. Clin. Nutr. 1991; 10: 18-22.

50 Lean ME, Han TS, Deurenberg P. Predicting body composition by densitometry from simple anthropometric measurements. Am. J. Clin. Nutr. 1996; 63(1): 4-14. 